\title{
CARACTERIZAÇÃO PATOGÊNICA, FISIOLÓGICA E MORFOLÓGICA DE Pseudocercospora musae*
}

\author{
REGINA C.T. ROSA \& MARIA MENEZES \\ Departamento de Agronomia, Área de Fitossanidade, Universidade Federal Rural de Pernambuco, \\ CEP 52171-900, Recife, PE; e-mail: reginactrosa@uol.com.br
}

(Aceito para publicação em 22/05/2001 )

Autor para correspondência: Regina Ceres Torres da Rosa

ROSA, R.C.T. \& MENEZES, M. Caracterização patogênica, fisiológica e morfológica de Pseudocercospora musae. Fitopatologia Brasileira 26:141-147. 2001.

\section{RESUMO}

As características patogênicas, fisiológicas e morfológicas de oito isolados de Pseudocercospora musae foram estudadas objetivando sua diferenciação. Para determinação da patogenicidade, os isolados foram inoculados em folhas de bananeira (Musa spp.) através de dois métodos: com e sem ferimento. Em ambos os casos, foram utilizados discos de micélio (4 mm de diâmetro), retirados de colônias jovens de cada um dos isolados. Maior eficiência na reprodução dos sintomas foi observada no método por ferimento, onde todos os isolados mostraram-se patogênicos, enquanto no sem ferimento, somente os isolados P-2 e P-4 apresentaram habilidade para penetrar e colonizar o tecido hospedeiro. Para a caracterização fisiológica, foi estudado o comportamento dos isolados em seis meios de cultura (BDA, V-8, leite de côco, Czapek, maltose-peptona e aveia) e três níveis de pH
(4,5; 5,5 e 6,5), durante o período de incubação de sete dias, a temperatura de $25{ }^{\circ} \mathrm{C}$ e em condições de alternância luminosa. Leite de coco, BDA e aveia induziram maior crescimento micelial, enquanto que $\mathrm{BDA}$, maltose-peptona, V-8 e Czapek, maior produção de conídios. Os isolados de $P$. musae cresceram melhor em $\mathrm{pH} 4,5$ e a esporulação foi favorecida em pH 6,5, destacando-se o isolado P-1 em relação aos demais. As características culturais dos isolados mostraram pequena variação quanto a topografia, coloração e pigmentação da colônia, de acordo com o substrato e $\mathrm{pH}$ empregados. A caracterização morfológica revelou variação não significativa no tamanho e na relação comprimento/ largura dos isolados de P. musae.

Palavras-chaves: Musa spp., patogenicidade, fisiologia, morfologia, Sigatoka amarela.

\section{ABSTRACT \\ Pathogenic, physiological and morphological characterization of Pseudocercospora musae}

The pathogenic, physiological and morphological characterization of eight Pseudocercospora musae isolates were studied. To determine pathogenicity, the isolates were inoculated on banana (Musa spp.) leaves, using two methods. The most efficience in the reproduction of the symptoms was observed in the wound method where all isolates showed pathogenicity, while without wounds, only P- 2 and P-4 isolates presented the ability to enter and colonize the host tissue. For the physiological characterization, the behavior of the eight isolates was studied in six culture media and three $\mathrm{pH}$ levels, during seven days of incubation at $25^{\circ} \mathrm{C}$, and alternated light. Coconut, potato dextrose agar, and oat media induced higher mycelial growth, while potato dextrose agar, MPA, V-8 juice and Czapek promoted higher production of conidia. The isolates of $P$. musae grew well at $\mathrm{pH} 4,5$, and the sporulation was favoured at $\mathrm{pH}$ 6,5. The cultural characteristics of the isolates showed little variation in topography, coloration, and pigmentation of the colony, according to the medium and $\mathrm{pH}$ level used. The morphological characterization showed little, but not significant, variation in size and conidial length/width ratio.

\section{INTRODUÇÃO}

A Sigatoka amarela, também chamada Cercosporiose da bananeira (Musa spp.), cujo agente causal é Pseudocercospora musae (Zimm.) Deighton (=Cercospora musae Zimmerman; teliomorfo: Mycosphaerella musicola

\footnotetext{
* Parte da dissertação de mestrado do primeiro autor apresentada a UFRPE (1990)
}

Leach ex Mulder), está entre as doenças mais frequientes e importantes da cultura no Brasil e no mundo. Os sintomas induzidos pela doença são caracterizados pela presença de estrias necróticas de coloração acinzentada com halo amarelo, paralelas às nervuras secundárias da folha. Estas estrias podem coalecer formando áreas necrosadas nas margens da folha. $\mathrm{O}$ dano atribuído à doença é a perda precoce das folhas, reduzindo a fotossíntese e, consequentemente, a produção (Bendezu \& Godinho, 1986). A planta emite cachos pequenos, 


\section{R. C. T. Rosa \& M. Menezes}

acelera a taxa de maturação dos frutos, conduz ao amadurecimento prematuro e resulta na diminuição da produção (Fouré, 1994; Medina et al., 1995). No Brasil, a Sigatoka amarela foi constatada, pela primeira vez, na cidade de São Sebastião-SP, por volta de 1935 , e o conhecimento de sua ocorrência endofitótica, só se verificou em 1944, no estado do Amazonas, estendendo-se posteriormente por todos os estados brasileiros (Dantas, 1948). Atualmente, além da Sigatoka amarela, há relatos no país da ocorrência da Sigatoka negra, causada por Paracercospora fijiensis (Morelet) Deighton (Teliomorfo: Mycosphaerella fijiensis Morelet), no estado do Amazonas (Cordeiro et al., 1998). Os sintomas são caracterizados inicialmente, por estrias de coloração marromavermelhada que posteriormente se tornam escuras, com o centro cinza, circundadas por um halo amarelo claro (Vieira, 1981), sendo esta última citada como mais severa a nível mundial. A distinção morfológica entre os agentes etiológicos da Sigatoka amarela e Sigatoka negra está na formação dos conidióforos, enquanto P. musae apresenta conidióforos em densos fascículos, retos, hialinos, septados, em estroma marrom a preto, e conídios medindo $10-109 \mu \mathrm{m}$ x $2-6 \mu \mathrm{m}$ (média 59-3 $\mu \mathrm{m}$ ), em $P$. fijiensis o conidióforo é simples ou em pequenos fascículos e os conídios medindo $30-132 \mu \mathrm{m} \mathrm{x}$ 2, 5 - $5 \mu \mathrm{m}$ (média 72, 5 - $4 \mu \mathrm{m}$ ), segundo Wardlaw (1972). Em geral, a obtenção de cultura pura de $P$. musae não é fácil, devido o fungo apresentar crescimento lento e baixa esporulação em substratos artificiais (Nagel, 1934; Dantas, 1948). Vários estudos objetivando a obtenção de condições favoráveis a esses processos fisiológicos envolvendo espécies de Cercospora foram realizados por diferentes pesquisadores, entre eles, Stavely \& Nimmo (1969), Silva et al. (1988), Del Peloso et al. (1989), Queiroz \& Menezes (1993), Ribeiro et al. (1997), principalmente enfatizando o efeito da nutrição e do ambiente. Com relação a $P$. musae, são encontrados na literatura os trabalhos de Dantas (1948), Stover (1965, 1970, 1971, 1976, 1980 e 1983), Simmonds (1959) e Wardlaw (1972). Neste sentido, a obtenção de condições ótimas para o crescimento e reprodução de $P$. musae em meios artificiais constitui um pré-requisito importante, facilitando a realização de vários estudos, relacionados com a biologia, genética e bioquímica do fungo, de modo a fornecer subsídios básicos para o entendimento da relação patógeno-hospedeiro como, também, para produção de conídios em quantidade suficiente, para inoculação de plantas visando a seleção de genótipos resistentes a doença. Considerando a importância da cultura e da doença, o presente trabalho teve como objetivo principal a obtenção de isolados de $P$. musae, a partir de material infetado, proveniente de diferentes áreas produtoras de banana, em Pernambuco, determinação da patogenicidade, caracterização morfológica e fisiológica do fitopatógeno.

\section{MATERIAL E MÉTODOS}

\section{Obtenção dos isolados}

Os isolados foram obtidos de folhas de bananeira 'pacovã', 'prata-anã' e 'missouri', exibindo sintomas típicos de Sigatoka amarela e coletadas em diferentes municípios do estado de Pernambuco. Pequenos fragmentos, retirados da área de transição da lesão, foram tratados com álcool 70\%, durante $30 \mathrm{~s}$ e desinfestados com uma solução de hipoclorito de sódio, numa concentração de $1,5 \%$, por 1-2 min. Em seguida, os fragmentos foram lavados em duas porções consecutivas de água destilada esterilizada, sendo logo depois colocados sobre papel de filtro estéril e transferidos para placas de Petri, contendo meio de batata-dextrose-ágar (BDA). Após o crescimento do fungo, fez-se a transferência, em condições assépticas, para tubos de ensaio contendo BDA, para os estudos subsequentes.

\section{Testes de patogenicidade}

Para o teste de patogenicidade foram utilizados segmentos de folhas de bananeiras cortadas em tiras de 6,5 $\mathrm{cm}$ de largura onde se procedeu a inoculação dos isolados, através de dois métodos: a) Deposição do inóculo na folha com ferimento: pequenos discos de micélio com $4 \mathrm{~mm}$ de diâmetro, retirados de colônias puras, foram depositados sobre a folha, previamente desinfestada e ferida com estilete flambado, em quatro pontos eqüidistantes; b) Deposição do inóculo na folha sem ferimento: neste método seguiu-se o mesmo procedimento do item "a", porém sem ferimentos. Para as testemunhas foram utilizados discos de ágar sem o inóculo, depositados na superfície foliar. As folhas inoculadas e testemunhas foram mantidas em câmara úmida, em condições de laboratório, por 30 dias, cobrindo-se as bandejas com sacos plásticos, internamente umedecidos com água destilada esterilizada. A avaliação foi efetuada levandose em consideração a presença ou ausência de sintomas necróticos.

\section{Caracterização fisiológica}

Para os estudos fisiológicos, os isolados de Pseudocercospora musae foram cultivados em diferentes meios de cultura, em três níveis de $\mathrm{pH}(4,5 ; 5,5$ e 6,5), num regime de alternância luminosa (12 h claro/ $12 \mathrm{~h}$ escuro), temperatura de $25{ }^{\circ} \mathrm{C}$ e umidade relativa de $60 \%$. Foram utilizados os seguintes meios de cultura: BDA (batata, $200 \mathrm{~g}$; dextrose, $20 \mathrm{~g}$; ágar, $17 \mathrm{~g}$ ); V-8 - ágar (suco V-8, $100 \mathrm{ml}$; $\mathrm{CaCO}_{3}, 2 \mathrm{~g}$; ágar, $17 \mathrm{~g}$ ); leite de coco - LC (leite de coco, 200 $\mathrm{ml}$; dextrose, $20 \mathrm{~g}$; ágar, $17 \mathrm{~g}$ ); Czapek - CZP (NaNO, $3 \mathrm{~g}$; $\mathrm{K}_{2} \mathrm{HPO}_{4}, 1 \mathrm{~g} ; \mathrm{MgSO}_{4} .7 \mathrm{H}_{2} \mathrm{O}, 0,5 \mathrm{~g} ; \mathrm{KCL}, 0,5 \mathrm{~g} ; \mathrm{FeSO}_{4} .7$ $\mathrm{H}_{2} \mathrm{O}, 0,01 \mathrm{~g}$; sacarose, $30 \mathrm{~g}$; ágar, 1, $5 \mathrm{~g}$ ); maltose-peptonaágar - MPA (maltose, $3 \mathrm{~g}$; peptona, $1 \mathrm{~g}$; ágar, $17 \mathrm{~g}$ ) e aveiaágar - AA (flocos de aveia, $20 \mathrm{~g}$; sacarose, $5 \mathrm{~g}$; ágar, $17 \mathrm{~g}$ ), em quantidade suficiente para $1.000 \mathrm{ml}$ de água destilada. De cada cultura pura dos isolados de $P$. musae, foram removidos discos de micélio (4 $\mathrm{mm}$ de diâmetro) e transferidos, individualmente, para o centro de placas de Petri, contendo os diferentes meios, sendo o $\mathrm{pH}$ ajustado para 4,5, 5,5 e 6,5. O delineamento estatístico utilizado foi inteiramente casualizado, em arranjo fatorial $6 \times 3$, representado pelos diferentes meios e níveis de $\mathrm{pH}$, perfazendo um total de 18 tratamentos para cada isolado, com três repetições para cada 
tratamento. A avaliação do crescimento micelial foi realizada através de medidas do diâmetro das colônias, em dois sentidos diametralmente opostos, com auxílio de uma régua milimetrada, aos sete dias de incubação, calculando-se a média. As características culturais analisadas foram topografia e coloração da colônia, considerando-se cada isolado de $P$. musae.

Após a avaliação do crescimento do fungo, procedeuse a quantificação da esporulação a partir do preparo da suspensão de conídios. Esta consistiu na remoção e transferência da colônia para tubos de ensaio, contendo $3 \mathrm{ml}$ de água destilada esterilizada, onde se procedeu a trituração com auxílio de um bastão de vidro e, em seguida, o material foi filtrado através de duas camadas de gaze. A concentração de conídios foi calculada pela média das leituras obtidas em dois campos da câmara de Neubauer. O delineamento estatístico utilizado foi o mesmo já citado anteriormente.

\section{Caracterização morfológica}

A caracterização morfológica foi efetuada utilizandose as culturas de $P$. musae que produziram conídios, sendo a avaliação feita com base no tamanho, cor e septação dos mesmos. Os dados foram analisados estatisticamente e as médias comparadas pelo teste de Tukey, ao nível de 5\% de probabilidade.

\section{RESULTADOS E DISCUSSÃO}

\section{Obtenção dos isolados}

Das folhas de bananeira analisadas foram obtidos vários isolados de $P$. musae, oito dos quais foram selecionados aleatoriamente (P-1, P-2, P-3, P-4, P-5, P-6, P-7, P-8), tomando-se como base o município de procedência do material. Apesar de P. musae não ser fácil de se isolar em meio de cultura artificial, devido apresentar crescimento muito lento, podendo ser mascarado pela presença de outros organismos, a metodologia empregada neste trabalho permitiu a obtenção de culturas puras do fungo, com sucesso.

\section{Testes de patogenicidade}

Os oito isolados de $P$. musae estudados revelaram-se patogênicos, quando inoculados em folhas de bananeira sadias pelo método de deposição com ferimento, enquanto que no método de inoculação sem ferimento, só os isolados P-2 e P4 apresentaram habilidade para penetrar e colonizar o tecido hospedeiro. Isto sugere uma maior eficiência do método de inoculação por ferimento, na reprodução de sintomas induzidos pelos isolados de P. musae. Após o período de 30 dias à inoculação, os tecidos foliares exibiram os sintomas típicos da doença, caracterizados pelo aparecimento de estrias amareladas com centros necróticos de coloração acinzentada. Os sintomas apresentados no teste de patogenicidade foram semelhantes aos obtidos por Vieira (1981) e McGahan \& Futon (1965). A colonização do patógeno estendeu-se além do ponto de inoculação, em sentido paralelo às nervuras secundárias.

\section{Caracterização fisiológica dos isolados de Pseudocercospora musae}

Considerando-se o efeito dos fatores independentes (isolados, meio de cultura e $\mathrm{pH}$ ), observou-se que a média do crescimento micelial de P-2 foi significativamente superior àquelas obtidas para os demais isolados de $P$. musae. Por outro lado, P-4 e P-5 apresentaram um crescimento mais lento, não diferindo entre si. Quanto ao fator meio de cultura, de um modo geral, LC, seguido de BDA e AA, induziram maior média de crescimento micelial de $P$. musae, não diferindo entre si, pelo teste de Tukey (Tabela 1). Embora na maioria dos casos, as diferenças não tenham sido significativas, observou-se maior crescimento micelial, quando os isolados foram cultivados em substratos com $\mathrm{pH} 4,5$. Na interação dos três fatores, meios x pH x isolados, os dados obtidos mostraram uma variação de comportamento de acordo com o substrato e nível de pH utilizados. As combinações que mais favoreceram o crescimento micelial de $P$. musae foram assim especificadas: a) P-2, melhor crescimento em LC e AA, nos três níveis de $\mathrm{pH}$, sendo o $\mathrm{pH}$ 4,5 aparentemente o mais favorável; b) P-3, P-6 e P-8, apresentaram maior crescimento no meio LC, nos três níveis de $\mathrm{pH}$, principalmente, 4,5 e 5,5; c) P-7, mostrou maior crescimento no meio de BDA, também nos três níveis de $\mathrm{pH}$, sendo 4,5 o mais favorável. Os resultados mostraram uma diferenciação no processo de crescimento, em função do efeito das condições de cultivo e também do próprio isolado (Tabela 1).

\section{Esporulação}

Dos isolados estudados, observou-se que a média da esporulação de P-6 foi significativamente superior àquelas obtidas para os demais isolados de P. musae. Por outro lado, P-3 e P-4 apresentaram uma menor produção de conídios, não diferindo entre si (Figura 1a). A esporulação nos diferentes meios de cultura estudados, revelou que os meios BDA, MPA e V-8 proporcionaram maior condição de esporulação de $P$. musae, nesse processo fisiológico, seguido do meio CZP com uma esporulação intermediária (Figura 1b). Não foi constatada a produção de esporos de nenhum dos isolados nos meios AA e LC, nos três níveis de $\mathrm{pH}$ estudados. Com relação a influência dos níveis $\mathrm{pH}$ na esporulação, observou-se que no pH 6,5 ocorreu produção mais abundante de conídios, porém não diferiu estatisticamente daquela obtida em pH 5,5 (Figura 1c). Os resultados da esporulação mostraram uma diferenciação de comportamento entre os isolados, de conformidade com as condições nutricionais a que foram submetidos. Assim, a maior produção de conídios foi constatada com relação ao isolado $\mathrm{P}-1$, quando cultivado no meio de BDA, em pH 6,5 (28 x $\left.10^{3} \mathrm{con} . / \mathrm{ml}\right)$, seguido pelos isolados P-6 (7,1 x 10 con./ $\mathrm{ml}$ em MPA) e P-8 (4,7 x 10 3 con./ml em CPZ), nas mesmas condições de $\mathrm{pH}$ (Figura 1d,e,f). $\mathrm{O}$ fato de um substrato ser considerado bom para o crescimento micelial de um fungo e nem sempre bom para a esporulação, já foi evidenciado com outros fitopatógenos (Lilly \& Barnett, 1951; Hawker, 1950; 1957; Cochrane, 1958; Griffin, 1994). Geralmente, a produção 
TABELA 1 - Efeito de meios de cultura e pH sobre o crescimento micelial, em mm, de oito isolados de Pseudocercospora musae, aos sete dias de incubação

\begin{tabular}{|c|c|c|c|c|c|c|c|c|}
\hline \multirow{2}{*}{ Isolado } & \multirow{2}{*}{$\mathbf{p} \mathbf{H}^{1}$} & \multicolumn{6}{|c|}{ Meios de cultura $^{2}$} & \multirow{2}{*}{ Média } \\
\hline & & $\mathbf{A A}$ & BDA & CZP & LC & MPA & V-8 & \\
\hline \multirow[t]{4}{*}{$\mathrm{P}-1$} & 4,5 & $7,0 \mathrm{aAB}$ & $8,7 \mathrm{aA}$ & $6,7 \mathrm{aAB}$ & $7,7 \mathrm{aA}$ & $5,3 \mathrm{aB}$ & $8,0 \mathrm{aA}$ & $7,2 \mathrm{a}$ \\
\hline & 5,5 & $7,0 \mathrm{aB}$ & $9,0 \mathrm{aA}$ & $6,0 \mathrm{abB}$ & $7,0 \mathrm{aB}$ & $5,3 \mathrm{aB}$ & $6,7 \mathrm{aB}$ & $6,9 \mathrm{a}$ \\
\hline & 6,5 & $7,7 \mathrm{aA}$ & $8,7 \mathrm{aA}$ & $4,5 \mathrm{aB}$ & $7,7 \mathrm{aA}$ & $4,5 \mathrm{aB}$ & $7,0 \mathrm{aA}$ & $6,7 \mathrm{a}$ \\
\hline & Média & $7,2 \mathrm{~B}$ & $8,8 \mathrm{~A}$ & $5,7 \mathrm{C}$ & $7,5 \mathrm{~B}$ & $5,0 \mathrm{C}$ & $7,2 \mathrm{~B}$ & 6,9 D \\
\hline \multirow[t]{4}{*}{$\mathrm{P}-2$} & 4,5 & $12,7 \mathrm{aA}$ & $11,6 \mathrm{aA}$ & $3,0 \mathrm{aC}$ & $12,0 \mathrm{aA}$ & $9,0 \mathrm{aB}$ & $11,0 \mathrm{aAB}$ & $10,0 \mathrm{a}$ \\
\hline & 5,5 & $11,0 \mathrm{aAB}$ & 9,7 abBC & $3,3 \mathrm{aD}$ & $12,4 \mathrm{aA}$ & $7,6 \mathrm{aC}$ & $10,7 \mathrm{aAB}$ & $9,2 \mathrm{~b}$ \\
\hline & 6,5 & $11,0 \mathrm{aA}$ & $10,3 \mathrm{bA}$ & $3,3 \mathrm{aC}$ & $11,0 \mathrm{aA}$ & $7,7 \mathrm{aB}$ & $9,7 \mathrm{aB}$ & $8,9 \mathrm{~b}$ \\
\hline & Média & $11,6 \mathrm{AB}$ & $10,6 \mathrm{~B}$ & $3,2 \mathrm{D}$ & $11,9 \mathrm{~A}$ & $8,1 \mathrm{C}$ & $10,4 \mathrm{~B}$ & 9,3 A \\
\hline \multirow[t]{4}{*}{$\mathrm{P}-3$} & 4,5 & $9,7 \mathrm{aA}$ & $10,7 \mathrm{aA}$ & $4,7 \mathrm{aB}$ & $11,5 \mathrm{aA}$ & $5,5 \mathrm{aB}$ & $10,2 \mathrm{aA}$ & 8,7 a \\
\hline & 5,5 & $10,2 \mathrm{aA}$ & $10,3 \mathrm{aA}$ & $4,7 \mathrm{aC}$ & $11,0 \mathrm{aA}$ & 7,0 abB & $9,2 \mathrm{aAB}$ & 8,7 a \\
\hline & 6,5 & $7,2 \mathrm{bB}$ & $9,7 \mathrm{aAB}$ & $4,3 \mathrm{aD}$ & $11,0 \mathrm{aA}$ & $7,7 \mathrm{bBC}$ & 9,3 aABC & $8,2 \mathrm{a}$ \\
\hline & Média & $9,0 \mathrm{~B}$ & $10,2 \mathrm{AB}$ & $4,6 \mathrm{D}$ & $11,2 \mathrm{~A}$ & $6,7 \mathrm{C}$ & $9,6 \mathrm{~B}$ & 8,5 B \\
\hline \multirow[t]{4}{*}{ P-4 } & 4,5 & $7,3 \mathrm{aA}$ & $6,8 \mathrm{aA}$ & $3,5 \mathrm{aB}$ & $7,0 \mathrm{aA}$ & $4,2 \mathrm{aB}$ & $7,0 \mathrm{aA}$ & $6,0 \mathrm{a}$ \\
\hline & 5,5 & $7,3 \mathrm{aA}$ & $6,7 \mathrm{aA}$ & $2,0 \mathrm{aB}$ & $6,3 \mathrm{aA}$ & $2,0 \mathrm{abB}$ & $6,3 \mathrm{abA}$ & $5,1 \mathrm{ab}$ \\
\hline & 6,5 & $7,7 \mathrm{aA}$ & $5,0 \mathrm{aBC}$ & $1,7 \mathrm{aD}$ & $6,0 \mathrm{aAB}$ & $3,0 \mathrm{bCD}$ & $5,2 \mathrm{bBC}$ & $4,8 \mathrm{~b}$ \\
\hline & Média & $7,4 \mathrm{~A}$ & $6,0 \mathrm{~A}$ & $2,4 \mathrm{~B}$ & $6,4 \mathrm{~A}$ & $3,1 \mathrm{~B}$ & $6,2 \mathrm{~A}$ & $5,3 \mathrm{E}$ \\
\hline \multirow[t]{4}{*}{ P-5 } & 4,5 & $8,0 \mathrm{aA}$ & $7,0 \mathrm{aAB}$ & $3,1 \mathrm{aC}$ & $5,0 \mathrm{aBC}$ & $5,3 \mathrm{aBC}$ & $4,7 \mathrm{aC}$ & $5,7 \mathrm{a}$ \\
\hline & 5,5 & $7,8 \mathrm{aA}$ & $7,3 \mathrm{aA}$ & $2,1 \mathrm{aC}$ & $6,0 \mathrm{aAB}$ & $6,3 \mathrm{aAB}$ & $4,3 \mathrm{aBC}$ & $5,6 \mathrm{a}$ \\
\hline & 6,5 & $7,8 \mathrm{aA}$ & $7,0 \mathrm{aA}$ & $3,0 \mathrm{aC}$ & $6,7 \mathrm{aAB}$ & $4,5 \mathrm{aBC}$ & $3,7 \mathrm{aC}$ & $5,4 \mathrm{a}$ \\
\hline & Média & $7,9 \mathrm{~A}$ & $7,1 \mathrm{AB}$ & $3,1 \mathrm{E}$ & $6,2 \mathrm{BC}$ & $5,2 \mathrm{CD}$ & $4,1 \mathrm{DE}$ & $5,6 \mathrm{E}$ \\
\hline \multirow[t]{4}{*}{ P-6 } & 4,5 & $9,3 \mathrm{aB}$ & $9,8 \mathrm{aAB}$ & $6,7 \mathrm{aC}$ & $12,0 \mathrm{aA}$ & $5,7 \mathrm{CD}$ & $9,3 \mathrm{aB}$ & $8,8 \mathrm{a}$ \\
\hline & 5,5 & $9,3 \mathrm{aB}$ & $10,0 \mathrm{aB}$ & $4,7 \mathrm{bD}$ & $12,5 \mathrm{abA}$ & $6,3 \mathrm{aCD}$ & $8,0 \mathrm{aBC}$ & $8,5 \mathrm{a}$ \\
\hline & 6,5 & $9,3 \mathrm{aB}$ & $10,7 \mathrm{aA}$ & $4,7 \mathrm{bD}$ & $10,3 \mathrm{bA}$ & $7,0 \mathrm{aC}$ & $8,0 \mathrm{aBC}$ & $8,3 \mathrm{a}$ \\
\hline & Média & $9,3 \mathrm{BC}$ & $10,2 \mathrm{~B}$ & $5,3 \mathrm{D}$ & $11,6 \mathrm{~A}$ & $6,3 \mathrm{D}$ & $8,4 \mathrm{C}$ & 8,5 B \\
\hline \multirow[t]{4}{*}{ P-7 } & 4,5 & $8,5 \mathrm{aB}$ & $11,5 \mathrm{aA}$ & $5,7 \mathrm{aC}$ & 7,7 aBC & $8,0 \mathrm{aB}$ & $7,0 \mathrm{aBC}$ & $8,1 \mathrm{a}$ \\
\hline & 5,5 & $9,3 \mathrm{aAB}$ & $10,7 \mathrm{aA}$ & $4,0 \mathrm{aD}$ & $8,0 \mathrm{aBC}$ & $7,3 \mathrm{aBC}$ & $7,0 \mathrm{aC}$ & $7,7 \mathrm{a}$ \\
\hline & 6,5 & $8,5 \mathrm{aAB}$ & $9,7 \mathrm{aA}$ & $4,3 \mathrm{aC}$ & $7,7 \mathrm{aAB}$ & $7,8 \mathrm{aAB}$ & $7,0 \mathrm{aB}$ & $7,5 \mathrm{a}$ \\
\hline & Média & $8,8 \mathrm{~B}$ & $10,6 \mathrm{~A}$ & $4,7 \mathrm{D}$ & $7,8 \mathrm{BC}$ & $7,7 \mathrm{BC}$ & $7,0 \mathrm{C}$ & $7,8 \mathrm{C}$ \\
\hline \multirow[t]{4}{*}{ P-8 } & 4,5 & $8,3 \mathrm{aB}$ & $8,3 \mathrm{aB}$ & $6,0 \mathrm{aC}$ & $10,8 \mathrm{aA}$ & $7,5 \mathrm{aBC}$ & $9,3 \mathrm{aAB}$ & $8,4 \mathrm{a}$ \\
\hline & 5,5 & $10,0 \mathrm{abA}$ & $7,0 \mathrm{abC}$ & $4,7 \mathrm{aD}$ & $10,0 \mathrm{bAB}$ & $6,7 \mathrm{aCD}$ & $8,0 \mathrm{abBC}$ & $7,8 \mathrm{ab}$ \\
\hline & 6,5 & $9,0 \mathrm{bA}$ & $6,3 \mathrm{bBC}$ & $5,7 \mathrm{aC}$ & $8,5 \mathrm{bAB}$ & 7,3 aABC & $7,3 \mathrm{bABC}$ & $7,4 \mathrm{~b}$ \\
\hline & Média & $7,2 \mathrm{AB}$ & $7,2 \mathrm{C}$ & $5,5 \mathrm{D}$ & $9,8 \mathrm{~A}$ & $7,2 \mathrm{C}$ & $8,2 \mathrm{BC}$ & 7,9 C \\
\hline Média & & $8,8 \mathrm{a}$ & $8,9 \mathrm{a}$ & $4,4 \mathrm{~d}$ & $9,0 \mathrm{a}$ & $6,2 c$ & $7,7 \mathrm{~b}$ & \\
\hline
\end{tabular}

C.V. $=13,1 \%$

D.M.S.(5\%): Interação = 2,39; $\mathrm{pH}=0,27 ;$ Meio $=0,46 ;$ Isolado $=0,57 ; \mathrm{pH} \times$ Meio $=0,79$;

$\mathrm{PH} \times$ Isolado $=0,76 ;$ Meio x Isolado $=1,3$

${ }^{1}$ Médias de três repetições para cada tratamento. Médias seguidas da mesma letra minúscula (vertical) e maiúscula (horizontal) não diferem, pelo teste de Tukey, ao nível de $5 \%$ de probabilidade.

${ }^{2} \mathrm{AA}=$ aveia; $\mathrm{BDA}=$ batata-dextrose-ágar; $\mathrm{CZP}=$ Czapek; $\mathrm{LC}=$ leite de côco; $\mathrm{MPA}=$ maltose-peptona-ágar; $\mathrm{V}-8=$ suco de oito vegetais.

de conídios ocorre quando há uma exaustão do meio, resultante da utilização dos nutrientes pelo fungo, durante a fase de crescimento vegetativo. Associadas a este processo, alterações na composição do meio podem ocorrer devido a metabólitos secundários liberados pelo fungo. Segundo Hawker (1957), a mudança de crescimento vegetativo para a esporulação depende principalmente do grau de maturidade do micélio, acelerado ou inibido pelas condições de cultivo. A variação de comportamento observada entre os isolados de P. musae, principalmente com relação à esporulação, pode ser explicada, possivelmente, por diferenças no potencial genético de cada um desses isolados, cuja expressão dos caracteres pode ocorrer em função do ambiente em que foi exposto. Esta suposição tem como base o trabalho de Hawker
(1950), quando estudou isolados monospóricos de 30 gêneros de fungos e verificou que $50 \%$ dos organismos analisados mostraram mais de um tipo de colônia. Considerando aquelas colônias originadas de um único conídio da mesma espécie, foram obtidos tipos miceliais com poucos conídios, tipos conidiais e tipos intermediários. Estes "tipos fisiológicos" foram correlacionados com o número de núcleos e tamanho de conídios, onde conídios grandes com mais de um núcleo produzem mais colônias intermediárias em diferentes níveis, do que conídios pequenos com um só núcleo.

Embora não tenham sido realizados estudos desta natureza, com os isolados de P. musae, no disco de micélio utilizado como inóculo, provavelmente existiam alguns conídios geneticamente diferentes, ou núcleos distintos no 
(a) Isolados

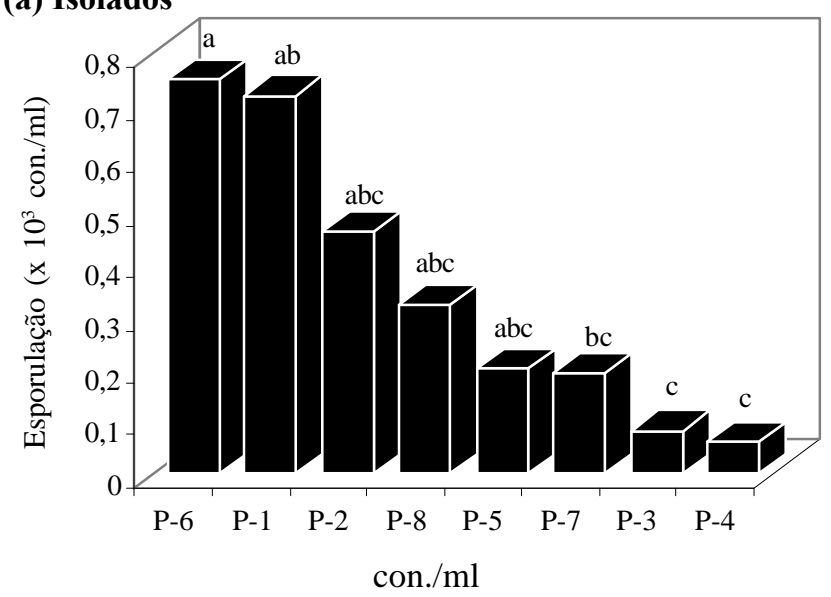

(b) Meios

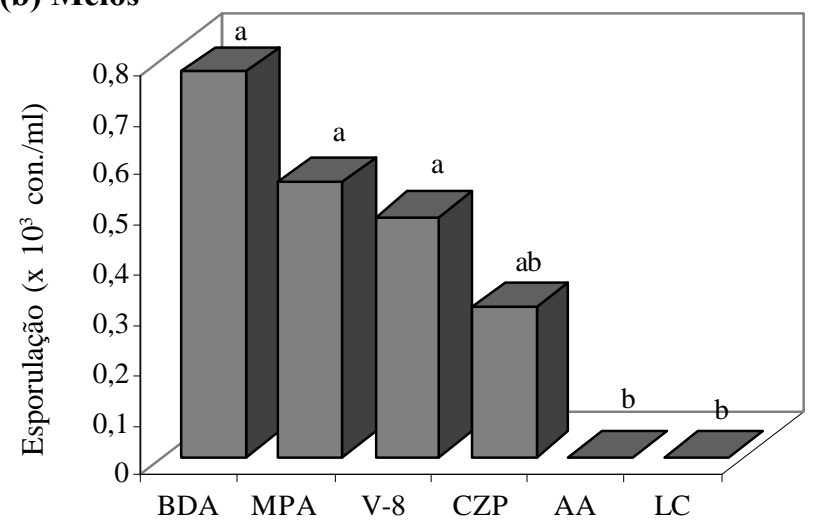

(c) $\mathrm{pH}$

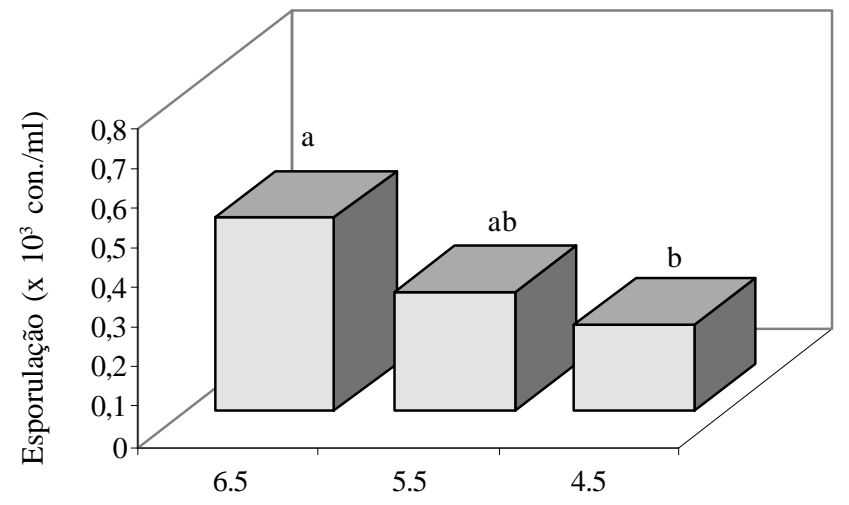

(d) $\mathrm{pH} \mathrm{4,5}$

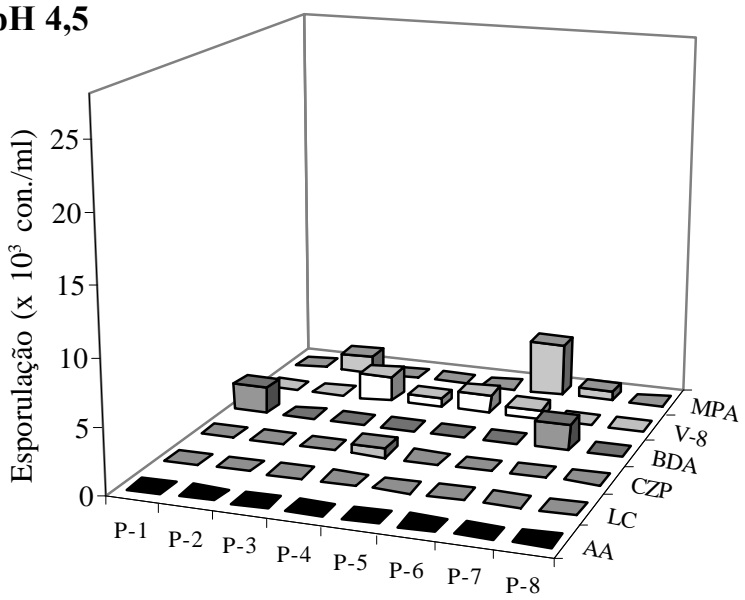

(e) pH 5,5

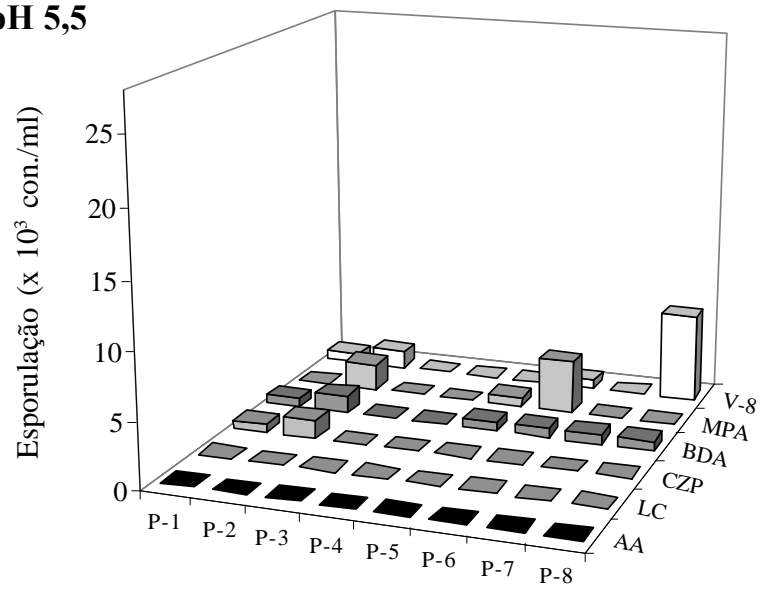

(f) pH 6.5

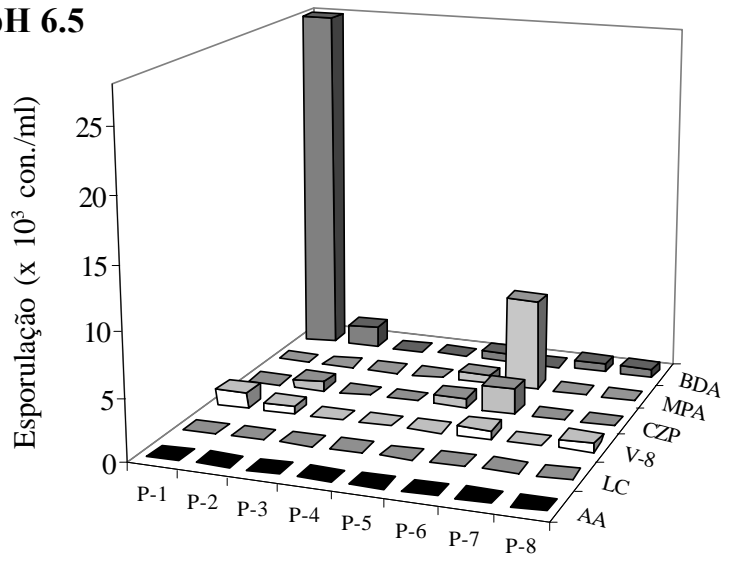

FIG. 1 - Efeitos independentes dos isolados (a), meios (b), níveis de pH (c) e das interações (d,e,f) na esporulação $10^{3}$ conídios/ml de Pseudocercospora musae. $\mathbf{A A}=$ aveia, $\mathrm{BDA}=$ batata-dextrose-agar, $\mathrm{CZP}=\mathrm{Czapek}$, $\mathrm{LC}=$ leite de coco, $\mathrm{MPA}=$ maltose-peptona-agar e $\mathrm{V}-8=$ suco de oito legumes.

próprio conídio, permitindo a variação de comportamento observada entre os isolados estudados. Essa variação também ocorreu em relação as características culturais, porém em menor grau. As colônias apresentaram uma coloração variando de verde acinzentado a escuro com predominância da primeira cor. Variação na coloração, também, foi observada por Stover (1976) em relação ao anamorfo de M. fijiensis que produziu dois tipos culturais: colônias verde-escuro ou verdeamarronzado com bordos crenados e colônias verde-pálido e rosa. Por outro lado, Dantas (1948) observou no meio de aveia um crescimento de $P$. musae limitado, convexo, tendo a colônia apresentado a base negra profundamente imersa no substrato, superficialmente revestida por um tênue micélio cotonoso, conferindo uma coloração rosada. $\mathrm{O}$ aspecto das 
colônias, quanto a presença de micélio rasteiro (plano) ou fofo (aéreo), variou em função do meio e dentro de um mesmo isolado. Em geral, os isolados apresentaram crescimento micelial plano nos meios de aveia (87,5\%), LC (75\%), MPA e V-8 $(62,5 \%)$ e em BDA e CZP (62,5\%) aéreo. O P-1 mostrou um crescimento plano nos meios BDA e $\mathrm{V}-8$, quando no $\mathrm{pH}$ 4,5 , enquanto nas demais condições de substrato, o micélio apresentou-se aéreo. Já o micélio do isolado P-8 foi aéreo no meio $\mathrm{V}-8$, pH 4,5 e plano nas demais condições. Do mesmo modo, a pigmentação do meio, produzida pelos isolados de P. musae variou de acordo com o meio empregado, o $\mathrm{pH}$ e o próprio isolado. No meio AA, o isolado $\mathrm{P}-1$ promoveu uma pigmentação rósea nos três níveis de $\mathrm{pH}$ estudados, enquanto o P-8 e P-6, somente no pH 6,5. No meio CPZ, os isolados P-3, P-4 e P-6 promoveram pigmentação nos três níveis de $\mathrm{pH}, \mathrm{P}-2$ nos níveis 5,5 e 6,5 e P-8 no nível 6,5. No meio de LC, a pigmentação rósea ocorreu nos isolados P-1 e P-4, nos três níveis de $\mathrm{pH}$. Segundo Lilly \& Barnett (1951) e Cochrane (1958), nos fungos, alguns pigmentos são acumulados no micélio e esporos, enquanto outros se difundem no meio de cultura. Esses pigmentos são em parte determinados por fatores genéticos e expressados pelo meio ambiente. Os fatores nutricionais que fazem com que os fungos produzam pigmentos no meio de cultura são os microelementos essenciais, as fontes de carbono e nitrogênio, o pH inicial do meio e a temperatura. Alguns pigmentos são conhecidos por serem antibióticos; outros, tal como o caroteno, são provitaminas, mas em geral, as funções desses pigmentos permanecem desconhecidas (Griffin, 1994).

Com relação a morfologia, os isolados de $P$. musae embora apresentando pequena variação no comprimento e largura dos conídios, bem como na relação comprimento/ largura, estas diferenças não foram significativas estatisticamente (Tabela 2). Com referência a septação, a maioria dos isolados apresentou de 1-5 septos, com predominância de três. Quanto a forma, foram observados conídios cilíndricos a obclavados-cilíndricos, retos ou curvos, hialinos a oliváceos, produzidos em conidióforos retos a ondulados, de coloração oliváceo pálido. Características muito próximas às descritas no presente trabalho foram citadas por Wardlaw (1972) para P. musae.

Em resumo, os resultados mostraram que as condições mais promissoras para crescimento e produção de conídios de $P$. musae envolveram o meio de BDA com o pH ajustado para 4,5 e 6,5, respectivamente. Essas condições servem de base para futuros estudos que visem a necessidade da produção de conídios em abundância para trabalhos de inoculação de plantas objetivando a identificação de fontes de resistência ao patógeno, entre outros aspectos.

\section{REFERÊNCIAS BIBLIOGRÁFICAS}

BENDEZU, J. M. \& GODINHO, F. P. A Sigatoka amarela. Informe Agropecuário 12:39-44. 1986.

COCHRANE, V.W. Physiology of Fungi. New York. J. wiley, 1958.

CORDEIRO, Z.J.M., MATOS, A.P. \& SILVA, S.O. La Sigatoka negra en Brasil. Infomusa 7:30-31. 1998.

DANTAS, B. A ocorrência da "Cercosporiose" da bananeira no Brasil, Cercospora musae Zimm. Boletim Técnico do Instituto Agronômico do Norte 14:1-29. 1948.

DEL PELOSO, M.C., FERNANDES, C.D., FILGUEIRAS, A.T. \& CHAVES, G.M. Esporulação de Cercospora coffeicola em diferentes meios de cultura. Fitopatologia Brasileira 14:41-44. 1989.

FOURÉ, E. Leaf spot diseases of banana and plantain caused by Mycosphaerella musicola and M. fijiensis. In: Jones, D.R. (Ed.) The improvement and testing of Musa: a global partnership. Honduras. International Network for the Improvement of Banana and Plantain (Inibap). 1994. pp. 37-46.

GRIFFIN, D.H. Fungal Physiology. New York. Willey-Liss, 1994.

HAWKER, L.E. Physiology of Fungi. London. London University Press. 1950.

HAWKER, L.E. The Physiology of Reproduction in Fungi. London. Cambridge University Press. 1957.

LILLY, V.G. \& BARNETT, H.L. Physiology of the Fungi. New York: McGraw-Hill. 1951. 464p.

McGAHAN, M.W. \& FUTON, R.H. Leaf spot of bananas caused by Mycosphaerella musicola: a comparative anatomical study of juvenile and adult leaves in relation to lesion morphology. Phytopathology 55:1179-11782. 1965.

TABELA 2 - Tamanho $(\mu \mathrm{m})$, comprimento (C), largura (L), relação (C/L) e septação dos conídios de Pseudocercospora musae

\begin{tabular}{|c|c|c|c|c|c|c|c|}
\hline \multirow{2}{*}{ Isolado } & \multicolumn{2}{|c|}{$\overline{\mathrm{C}}$} & \multicolumn{2}{|c|}{$\overline{\mathbf{L}}$} & \multirow{2}{*}{$\mathrm{C} / \mathrm{L}$} & \multicolumn{2}{|c|}{ Número de septos } \\
\hline & Variação & Média $^{1}$ & Variação & Média $^{1}$ & & Variação & Predominância \\
\hline $\mathrm{P}-1$ & $23,1-89,1$ & 55,3 & $2,6-4,5$ & 3,3 & 16,8 & $0-5$ & $2(47 \%)$ \\
\hline $\mathrm{P}-2$ & $49,5-99,0$ & 64,4 & $2,3-4,6$ & 3,3 & 19,5 & $1-5$ & $3(60 \%)$ \\
\hline P-3 & $19,8-69,3$ & 45,0 & $2,6-3,3$ & 3,2 & 14,1 & $1-5$ & $3(40 \%)$ \\
\hline P-4 & $33,0-85,8$ & 55,1 & $3,3-5,3$ & 3,6 & 15,3 & $1-5$ & $3(50 \%)$ \\
\hline P-5 & $33,0-102,3$ & 59,3 & $2,3-6,6$ & 3,4 & 17,4 & $1-5$ & $3(50 \%)$ \\
\hline P-6 & $26,4-105,6$ & 57,9 & $2,6-4,6$ & 3,7 & 15,7 & $0-5$ & $3(60 \%)$ \\
\hline P-7 & $23,1-99,0$ & 59,8 & $2,6-8,3$ & 4,6 & 13,0 & $0-5$ & 3 e $4(23 \%)$ \\
\hline P-8 & $23,1-95,7$ & 47,5 & $2,6-4,6$ & 3,3 & 14,4 & $1-5$ & $3(47 \%)$ \\
\hline
\end{tabular}

30 conídios/isolado; médias não significativas pelo teste de Tukey a $5 \%$ de probabilidade. 
MEDINA, J.C., BLEINROTH, E.W., DE MARTIN, Z.J., TRAVAGLINI, D.A., OKADA, M., QUAST, D.G., HASHIZUME, T., MORETTI, V.A., BICUDO NETO, L.C., ALMEIDA, L.A.S.B. \& RENESTO O.V. Banana: cultura, matéria-prima, processamento e aspectos econômicos. 2 ed. Campinas. ITAL. 1995.

NAGEL, C.M. Conidial production in species of Cercospora in pure culture. Phytopathology 24: 1101-1110. 1934.

QUEIROZ, F.M. \& MENEZES, M. Efeito de meios de cultura e do regime de luz na esporulação de Cercospora nicotianae. Fitopatologia Brasileira 18:545-547. 1993.

RIBEIRO, Z.M.A., MELLO, S.C.M., FURLANETTO, C., FIGUEIREDO, G. \& FONTES, E.M.G. Characteristics of Cercospora caricis, a potencial agent of Cyperus rotundus. Fitopatologia Brasileira 22:513-519. 1997.

SILVA, M.F., CAVALCANTE, M.A., POROCA, D.M. \& LIMA, D.M. Cultivo e esporulação de Cercospora caribaea e $C$. henningsii, agentes causais de manchas foliares em mandioca. Fitopatologia Brasileira 13:5458. 1988.

SIMMONDS, N.W. Bananas. London. Longmans. 1959.

STAVELY, J.R. \& NIMMO, J.A. Effects of temperature upon growth and sporulation of Cercospora nicotianae.
Phytopathology 59:496-498. 1969.

STOVER, R.H. Bananas leaf spot caused by Mycosphaerella musicola: contrasting features of Sigatoka and black leaf streak control. Plant Disease 55:437-439. 1971.

STOVER, R.H. Distribution and cultural characteristics of the pathogens causing banana leaf spot. Tropical Agriculture 53:111-114. 1976.

STOVER, R.H. Leaf spot of bananas caused by Mycosphaerella musicola: effect of temperature on germination, hyphal growth, and conidia production. Tropical Agriculture 42:351-360. 1965.

STOVER, R.H. Leaf spot of bananas caused by Mycosphaerella musicola: role of conidia in epidemiology. Phytopathology 60:856-860. 1970.

STOVER, R.H. Sigatoka leaf spot of bananas and plantains. Plant Disease 64:750-756. 1980.

STOVER, R.H. The effect of temperature on germ tube growth of M. musicola and M. fijiensis var. disformis. Fruits 38:625-628. 1983.

VIEIRA, G.M. Investigações sobre o "Mal de Sigatoka" ou Cercosporiose da bananeira (Musa spp.). Recife, UFRPE, 1991. Monografia.

WARDLAW, C. W. Banana Diseases Including Plantains and Abaca. 2.ed. London. Longman. 1972. 